TERRA. Revista de Desarrollo Local e-ISSN: 2386-9968

Número 6 (2020), 302-312

DOI 10.7203/terra.6.16776

IIDL - Instituto Interuniversitario de Desarrollo Local

\title{
El Plan de Gobernanza y Dinamización Turística del Camp de Morvedre (Valencia, España)
}

\author{
Isaac Hernández Ferrer \\ Agente de Empleo y Desarrollo Local de la Mancomunidad de 'La Baronía' (Valencia, \\ España) \\ aedl@mancomunidadlabaronia.es
}

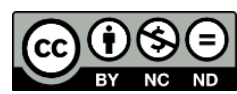

Esta obra se distribuye con la licencia Creative Commons Reconocimiento-NoComercial-SinObraDerivada 4.0 Internacional 


\section{SECCIÓN EXPERIENCIAS Y BUENAS PRÁCTICAS}

\section{El Plan de Gobernanza y Dinamización Turística del Camp de Morvedre (Valencia, España)}

Resumen: El Plan de Gobernanza y Dinamización Turística del Camp de Morvedre pretendía impulsar las líneas de trabajo que se venían desarrollando anteriormente en los diferentes municipios de la comarca, para dotar de una visión territorial meso-escalar a la estrategia turística de la zona, consensuando las líneas de trabajo y las actuaciones, no solamente con otras administraciones locales, sino también con actores del sector privado y asociaciones relacionadas con el sector turístico. El Plan también estaba centrado en la detección de recursos con potencial turístico que estuviesen infrautilizados o fueran susceptibles de ser puestos en valor, prestando especial atención a entornos que pudieran ser revalorizados, pero que en su estado actual no aportaban valor al sector turístico. También se hacía hincapié en la generación y creación de productos y paquetes turísticos, trabajando sobre recursos que existían actualmente pero que no eran atractivos para la demanda turística, con el fin de producir una mejora y que pudieran ser competitivos. Hablamos especialmente de productos de turismo activo, natural, gastronómico, turismo accesible, cinematográfico o similar. El Plan constaba en su inicio de un desarrollo de tres años. Tres años orientados a recabar toda la información necesaria para poder elaborar un plan estratégico que recogiera las diferentes visiones del sector turístico, detallar todas las actuaciones a realizar, y por supuesto, ejecutarlas. Aunque el Plan conllevaba una inversión por parte de las principales entidades participantes, el objetivo era crear una red que trascendiera el ámbito espacial del propio Plan y de la inversión inicial, y que sirviera de motor para continuar trabajando de forma conjunta tanto el sector público como el privado a lo largo de los años. El Plan de Gobernanza y Dinamización Turística del Camp de Morvedre ha conseguido el impacto que buscaba. No obstante, queda muchísimo trabajo por hacer, pero ha logrado otorgar la identidad suficiente al conjunto de la comarca del Camp de Morvedre para poder promocionarse como destino cohesionado, creando sinergias entre los recursos.

Palabras clave: Planificación, desarrollo local, turismo, gobernanza, participación.

Recibido: 28 de febrero de 2020

Devuelto para revisión: 28 de febrero de 2020

Aceptado: 03 de marzo de 2020

\section{Referencia / Citation:}

Hernández, I. (2020). El plan de gobernanza y dinamización turística del Camp de Morvedre (Valencia, España). TERRA. Revista de Desarrollo Local, (6), 302-312. DOI 10.7203/terra.6.16776 


\section{INTRODUCCIÓN}

El Camp de Morvedre es una comarca situada al norte de la provincia de Valencia, colindante con la provincia de Castellón, formada por un total de 16 municipios: Albalat dels Tarongers, Alfara de la Baronía, Algar de Palancia, Algimia d'Alfara, Benavites, Benifairó de les Valls, Canet d'en Berenguer, Estivella, Faura, Gilet, Petrés, Quart de les Valls, Quartell, Sagunto (el más grande en cuanto a extensión y población), Segart y Torres Torres. Excepto Canet d'en Berenguer y Sagunto, el resto de municipios están agrupados en dos Mancomunidades, la Mancomunitat de la Baronia y la Mancomunitat de les Valls.

El Camp de Morvedre ha sido conocido tradicionalmente por sus playas y tiene una grandísima afluencia de turistas en el periodo estival, que se concentran principalmente en Sagunto y Canet d'en Berenguer. No obstante, la comarca posee una gran cantidad de recursos aparte de las playas, como un gran patrimonio histórico, cultural y natural, cuyo potencial turístico queda todavía por explotar.

Con la idea de poner en valor todos los recursos existentes, hacer del Camp de Morvedre un destino aún más atractivo y aumentar la competitividad del sector turístico en la comarca, en el año 2016 se inició un ambicioso proyecto que involucraba a todos los actores del sector, especialmente a las administraciones públicas. Se trata del Plan de Gobernanza y Dinamización Turística del Camp de Morvedre.

\section{EL PLAN DE GOBERNANZA Y DINAMIZACIÓN TURÍSTICA DEL CAMP DE MORVEDRE}

Los Planes de Gobernanza y Dinamización Turística se han desarrollado en diferentes comarcas de la Comunitat Valenciana durante los últimos años, y suponen una suma del esfuerzo de todos los actores turísticos de un territorio. Se trata de una visión para abordar el desarrollo turístico de forma estratégica, planificada y desde un punto de partida supramunicipal, tratando de evitar la "política de campanario", de forma que se establezcan y se trabajen los objetivos de forma conjunta (Farinós et al., 2018). Estos planes contribuyen al reequilibrio entre los espacios litorales, tradicionalmente más dinámicos y competitivos con los territorios de interior, que en la actualidad ostentan un mayor margen de desarrollo y crecimiento.

El Plan de Gobernanza y Dinamización Turística del Camp de Morvedre pretendía impulsar las líneas de trabajo que se venían desarrollando anteriormente en los diferentes municipios de la comarca, para dotar de una visión territorial meso-escalar a la estrategia turística de la zona, consensuando las líneas de trabajo y las actuaciones, no solamente con otras administraciones locales, sino también con actores del sector privado y asociaciones relacionadas con el sector turístico.

El Plan también estaba centrado en la detección de recursos con potencial turístico que estuviesen infrautilizados o fueran susceptibles de ser puestos en valor, prestando especial atención a entornos que pudieran ser revalorizados, pero que en su estado actual no aportaban valor al sector turístico. También se hacía hincapié en la generación y creación de productos y paquetes turísticos, trabajando sobre recursos que existían actualmente pero que no eran atractivos para la demanda turística, con el fin de producir una mejora y 
que pudieran ser competitivos. Hablamos especialmente de productos de turismo activo, natural, gastronómico, turismo accesible, cinematográfico o similar.

El Plan constaba en su inicio de un desarrollo de tres años. Tres años orientados a recabar toda la información necesaria para poder elaborar un plan estratégico que recogiera las diferentes visiones del sector turístico, detallar todas las actuaciones a realizar, y por supuesto, ejecutarlas. Aunque el Plan conllevaba una inversión por parte de las principales entidades participantes, el objetivo era crear una red que trascendiera el ámbito espacial del propio Plan y de la inversión inicial, y que sirviera de motor para continuar trabajando de forma conjunta tanto el sector público como el privado a lo largo de los años.

\subsection{Inicio proyecto}

Durante el año 2016 se empiezan a iniciar los contactos para arrancar el proyecto, comenzando por su vertiente más administrativa, relativa a la firma del convenio marco y de la adhesión de todos los municipios de la comarca tras las respectivas votaciones por los Plenos municipales. Ya entonces se establecen las primeras acciones a desarrollar, aunque con muy poco margen temporal para ejecutarlas; no obstante, todos los ayuntamientos de la comarca se comienzan a adherir al Plan de Gobernanza y Dinamización Turística y da comienzo un Plan que, teniendo en mente el horizonte temporal de las tres anualidades, establece unas acciones concretas en cada una de ellas.

En la fase inicial, correspondiente al año 2016 y principios de 2017, se establece la realización de un estudio previo de la demanda turística para conocer en profundidad el estado actual, y determinar con mayor exactitud que turistas nos visitan y dónde existe cierto margen de mejora. Dado que uno de los objetivos principales del Plan era lograr la diversificación del turismo de sol y playa, sin renunciar al mismo, se desarrolla paralelamente al estudio un análisis de los recursos turísticos de la comarca desde el punto de vista de la accesibilidad.

También comienzan a definirse rutas senderistas y cicloturistas "La Mar entre Marjals" y la "Ruta de la Sequia Major", rutas que ponían el foco en los recursos naturales y en la vertebración de la comarca, al mismo tiempo que se proyectan acciones para la mejora de las playas.

Los primeros meses fueron costosos en cuanto a la movilización de todos los agentes locales para poder concretar administrativamente el plan, y comenzar a trabajar de forma conjunta con todos ellos. Sin embargo, una vez tomado el contacto y establecido unas líneas de trabajo iniciales, se comienza a planificar las acciones que definirán el Plan.

\subsection{Mesa comarcal de turismo}

A lo largo de todo el Plan, encontramos un tema recurrente: la necesidad de seguir contando con una estructura de trabajo que permita dar continuidad a lo avanzado una vez finalicen las tres anualidades del Plan propiamente dicho; es decir, se presenta la necesidad de establecer un órgano participativo que dé continuidad al proyecto más allá de la subvención.

La gestoría del Plan establece las líneas a seguir, ahondando en varios aspectos, especialmente en la creación de una mesa comarcal de turismo que reúna a los actores más destacados y que participen de forma activa en el sector turístico en la comarca. Este 
objetivo arranca con la realización de un proceso participativo para presentar, crear y consolidar redes entre los diferentes actores, dar voz a entidades locales, asociaciones y a empresarios del sector, estableciendo propuestas consensuadas y teniendo como objetivo desarrollar un plan integral. El proceso se compuso de numerosas entrevistas, recogida de información y realización de talleres para trabajar en conjunto, utilizando técnicas como el famoso modelo canvas (Figura 1).

Figura 1. Taller de trabajo de Impulso de la mesa comarcal de turismo

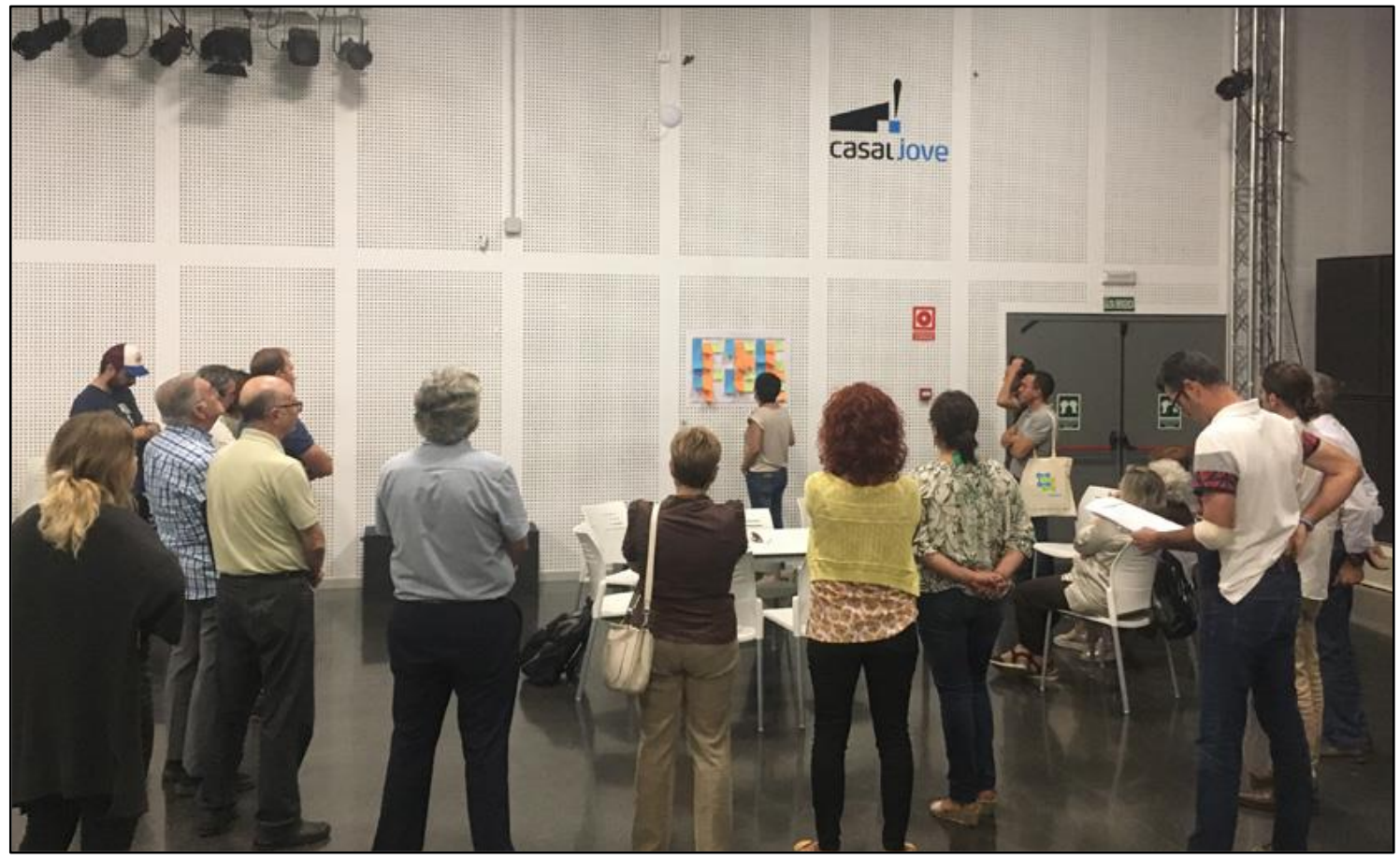

Fuente: Ayuntamiento de Sagunto. Septiembre de 2018. Casal Jove Puerto de Sagunto.

Se contactó con numerosas asociaciones relacionadas con el sector de los diferentes municipios, empresarios de referencia, técnicos de turismo, agentes de desarrollo local, alcaldes y concejales, comerciantes, etc. Durante el proceso se trataron variedad de asuntos clave para el desarrollo turístico, entre ellos el propio modelo turístico en sí, cuyo eje central era (y es) la sostenibilidad. También se hizo hincapié en la forma de promoción del destino, en el público objetivo o tipo de turista que acude a la comarca, las potencialidades del turista nacional e internacional, los canales de comunicación para hacer llegar la información, y las virtudes del territorio al público adecuado.

Se realizaron numerosas entrevistas y varias sesiones conjuntas a fin de reflejar con la mayor exactitud posible la realidad de la zona, teniendo en cuenta el punto de vista de los diferentes actores, tanto del sector público como del privado.

El resultado del proceso fue la elaboración de un documento de partida para la creación de la mesa comarcal de turismo, cuyo objetivo principal era mantener esas redes creadas durante el proceso, y paralelamente consolidar el modelo de dirección estratégica del sector turístico en el Camp de Morvedre. El documento fue presentado ante toda la comarca en acto público. 


\subsection{Innovación en el sector turístico}

Otra de las líneas de trabajo del Plan era el impulso de la innovación en el sector turístico de la comarca, centrado en la atención e información proporcionada al turista. Por la propia tipología del territorio encontramos dos municipios muy desarrollados en cuanto a atención al turista: Canet d'en Berenguer y Sagunto, con una y dos oficinas de Tourist Info respectivamente. En el resto de los municipios de la comarca, al no disponer de oficina específica, la información es aportada en los propios ayuntamientos, únicamente en horario de oficina.

Existía pues una necesidad de gran parte de la comarca de ofrecer información turística fiable más allá de los límites municipales, es decir, si los municipios pretenden crear sinergias entre sus recursos, todos los puntos de información al turista deben manejar la misma información, y que la persona que solicite información en Algar de Palancia o Sagunto, por poner un ejemplo, pueda recibir el mismo contenido.

En el Plan, esta necesidad se pretendía superar con el uso de las nuevas tecnologías, mediante la creación de una plataforma de información común, que se alimentara del contenido de todos y cada uno de los municipios participantes, siendo accesible por parte de las personas encargadas de ofrecer información. Es decir, hablamos de una plataforma interna y que permitiese obtener la información que el turista necesitase.

En el 2018 se inició esta parte del proyecto, con la recogida de información turística de todos los recursos, eventos, horarios, lugares y, en definitiva, de cualquier cuestión que pudiera ser de interés para el turista que visitara la comarca. Con esta información se creó la base de datos inicial para poner en marcha la "intranet", aunque la creación de esa plataforma seguía sin solucionar uno de los problemas de los municipios más pequeños. Estos municipios ofrecen la información al turista desde el propio ayuntamiento, con la consiguiente limitación horaria, por poner un ejemplo, durante los fines de semana, tradicionalmente con mucho más flujo de visitantes y turistas, precisamente cuando la gran mayoría de ayuntamientos permanecen cerrados.

Teniendo en mente esta problemática se optó por incluir en el proyecto la instalación de unas pantallas de información turística en los municipios que no disponen de oficina de "Tourist Info", de forma que el turista tuviese un punto 24/7 donde acudir a solicitar la información. Inicialmente se instalaron tres pantallas, una en Canet d'en Berenguer, otra en Algar de Palancia y otra en Benifairó de les Valls, quedando pendiente para las próximas anualidades la instalación de estas pantallas táctiles en el resto de los municipios. Desde estas pantallas, el turista puede descargar la información a su smartphone o tableta, pudiendo llevarse la información a cualquier lado, no siendo necesario estar físicamente delante de la pantalla para consultar la información solicitada.

Por otro lado, a nivel de evaluación de la actividad turística, la intranet permite recopilar la información en cuanto a tipología de consultas o procedencia de los turistas que son de gran valor para conocer las características de los turistas que nos visitan, y realizar una planificación más acertada, atendiendo a sus intereses.

\subsection{Plan de marketing}

Entre las acciones del Plan de Gobernanza y Dinamización Turística se encontraba la elaboración de un plan de marketing, cuyo objetivo era establecer las pautas para presentar la comarca del Camp de Morvedre en su totalidad como un destino turístico competitivo y con gran cantidad de recursos. 
Hasta ese momento, la promoción turística de los diferentes municipios de la comarca se había desarrollado principalmente de forma individual, a excepción de algunas colaboraciones puntuales o la promoción hecha a través de las mancomunidades de la Baronía y la de Les Valls, con lo que no existía una imagen conjunta como comarca.

Por ello se trabajó en la creación de una marca comarcal, un logotipo destinado a su uso turístico que creara esa identidad de comarca y fuera asociado no solamente a las acciones desarrolladas dentro del plan turístico, sino también a cualquier acción desarrollada por cualquiera de los municipios. La marca se configura como pieza básica a la hora de promocionar el destino en los diferentes eventos y ferias que se celebran (Figura 2).

Referente a las acciones de marketing, a lo largo del plan se han desarrollado las habituales acciones tanto en redes sociales como en medios para promocionar el sector turístico de la comarca, recursos, lugares, eventos y por supuesto el propio plan. Cabe destacar la campaña \#seabreeltelon con varios spots dirigidos a promocionar la comarca en su conjunto.

Figura 2. Logo del Plan de Gobernanza y Dinamización Turística del Camp de Morvedre

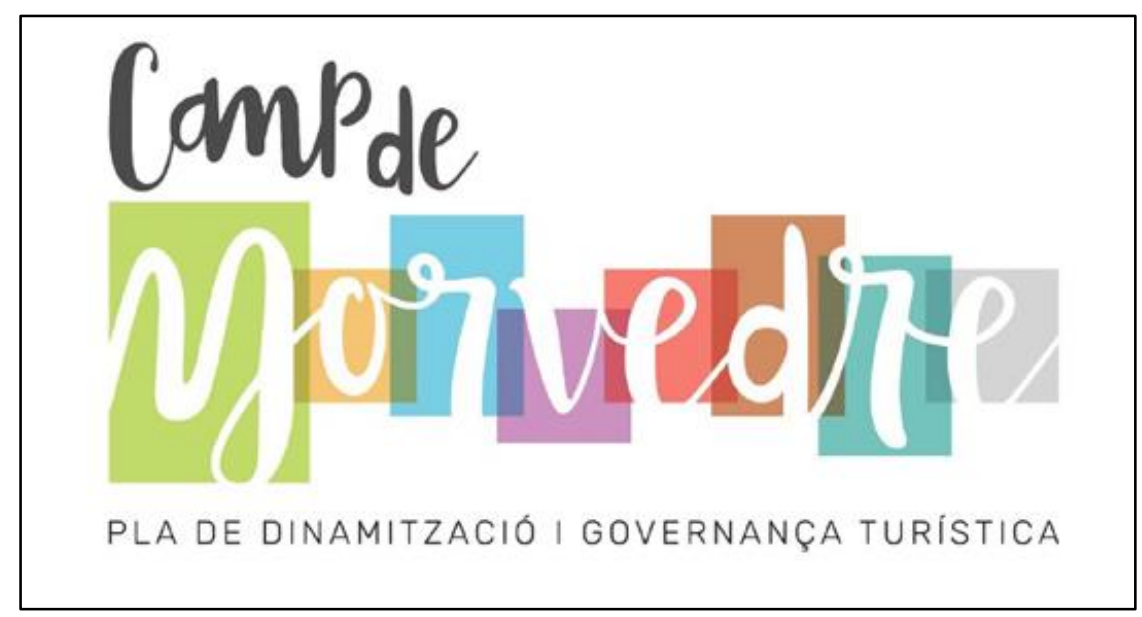

Fuente: Ayuntamiento de Sagunto. (https://bit.ly/2VBn5NZ)

\subsection{Film office}

Durante las dos primeras anualidades del Plan se estuvo desarrollando una de las piezas claves en cuanto a la puesta en escena de la comarca del Camp de Morvedre a nivel turístico: el "Film Office". La idea era desarrollar una base de datos de ubicaciones y lugares que tuvieran un atractivo especial para poder realizar grabaciones de cualquier tipo. Finalmente, estas se recopilaron en una web accesible a todos los públicos, pero dirigida especialmente a todas las productoras con interés en grabar en la comarca. Esta oficina ${ }^{1}$, que tiene en la web su carta de presentación, pretende ser un sistema claro y directo a la hora de ofrecer información relativa a lugares, condiciones y requisitos para grabar en la comarca.

En el diagnóstico inicial se concluyó que la comarca posee una cantidad de localizaciones con un alto potencial para acoger rodajes de series o películas. Con el paso del tiempo se ha comprobado como definitivamente esta Film Office está comenzando a dar sus frutos, pues disponemos ya de ejemplos de rodajes destacados que se han realizado en la

\footnotetext{
${ }^{1}$ https://www.saguntofilmoffice.com/
} 
comarca, como es el caso de la serie "Perdida", cuya parte de la trama se desarrolla en el "Grau Vell" de Sagunto (Figura 3).

La proyección turística que puede otorgar una serie o película de éxito rodada en la comarca es bastante reseñable, tal y como se ha ido demostrando en casos concretos, incluso en la propia Comunitat Valenciana, siendo un caso de éxito muy sonado el municipio de Peñíscola en la serie de televisión "El chiringuito de Pepe" o el considerable incremento de turistas en Gaztelugache, País Vasco, tras ser escenario de algunos episodios de la famosa serie "Juego de Tronos".

Figura 3. Portada de la web de la "Film Office" del Camp de Morvedre

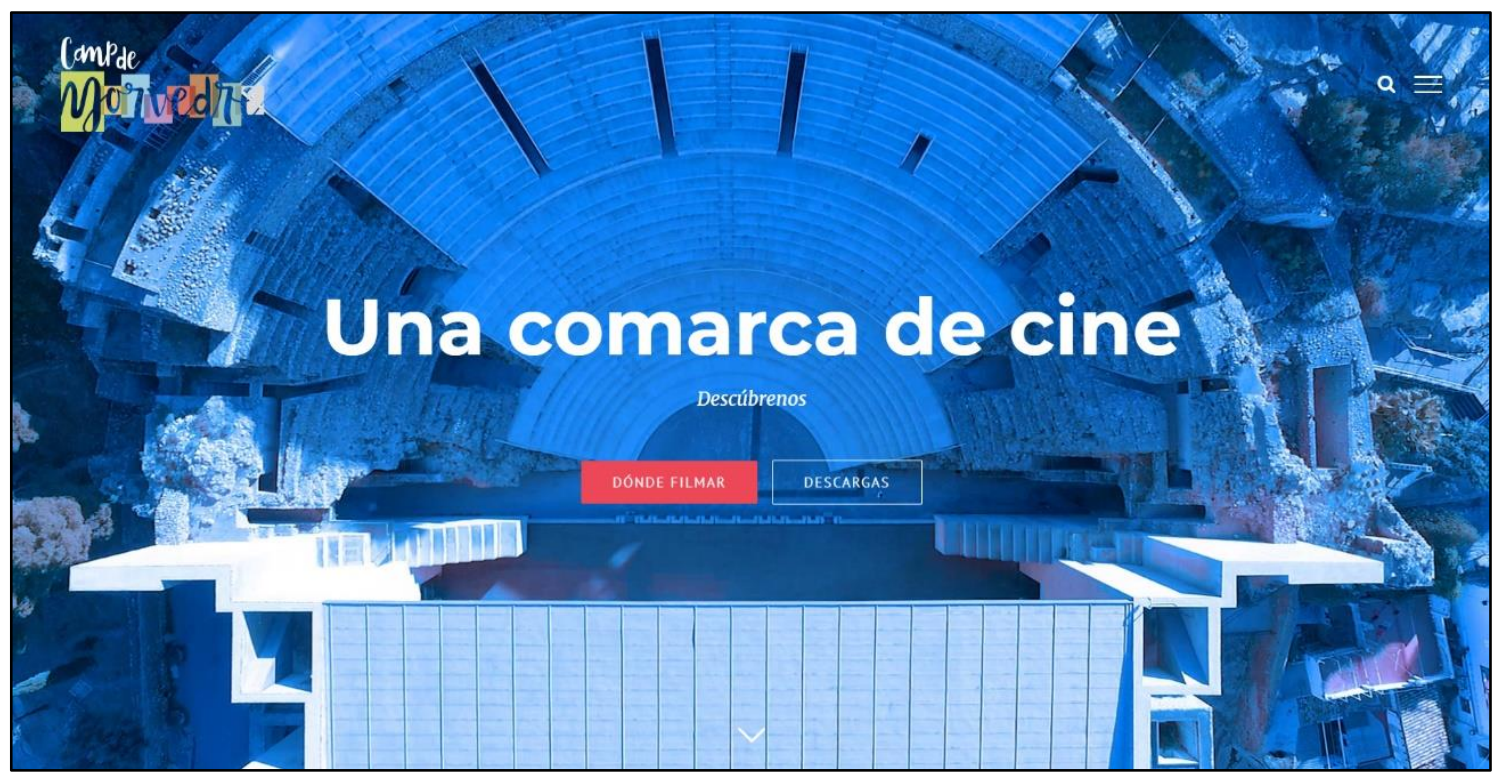

Fuente: Film Office del Camp de Morvedre (https://www.saguntofilmoffice.com/).

\subsection{Diversificación en el producto turístico, más allá del turismo de sol y playa}

En la comarca encontramos un producto de turismo de sol y playa muy competitivo. El trabajo realizado por Sagunto y Canet d'en Berenguer por ofrecer unas playas de altísima calidad ha dado sus frutos durante más de dos décadas, siendo una zona destacada por sus playas dentro de un entorno tan excelente en este aspecto como es la Comunitat Valenciana.

No obstante, en la comarca existen muchísimos más recursos turísticos. Así, por ejemplo, sin salir de Sagunto encontramos un patrimonio histórico y cultural muy rico: el castillo, el teatro romano, la zona de la judería y numerosos restos arqueológicos. En la zona del puerto, existe actualmente un gran patrimonio industrial, herencia de los altos hornos y de la actividad que hace años allí se desarrollaba.

Pero también dentro de la comarca encontramos patrimonio histórico y cultural, caso de los baños árabes en Torres Torres, el castillo de Beselga, el de Petrés, el de Torres Torres, la ruta del agua comarcal, que cruza varios municipios y "riega" el territorio de aljibes, cisternas, lavaderos y, en general, infraestructuras relacionadas con el agua que poseen un alto valor histórico, siendo algunos declarados bienes de interés cultural.

Sumando al patrimonio ya mencionado encontramos una gran zona natural, la ubicación de la comarca, especialmente en los municipios ubicados junto a la Sierra Calderona. 
Tenemos el mirador del Garbí, la Vía Verde Ojos Negros, multitud de rutas senderistas, entre ellas el paso del GR-10 y, en general, un espacio magnífico para la práctica del turismo de naturaleza y el turismo deportivo (Velarde y Escribano, 2016).

El Plan de Gobernanza y Dinamización Turística buscaba aunar la suma de todos estos recursos, para ser un destino turístico compacto, pero en especial, y debido a las posibilidades de crecimiento y de puesta en valor buscó centrarse en la diversificación del producto turístico. Esto es, acciones a desarrollar con los productos turísticos menos explotados hasta la fecha, siempre con el eje central de la sostenibilidad.

Por todo lo expuesto, se planificaron acciones encaminadas a producir una diversificación del producto, entre ellas cabría destacar la planificación de la creación de un museo interpretativo de la Vía Verde Ojos Negros, la promoción del producto gastronómico en la comarca, que, aunque en la actualidad está en un estado muy embrionario, se detectó que tiene un potencial interesante, o la mejora de productos de turismo deportivo de litoral.

Otra de las acciones destacadas fue la promoción del turismo de natura, con la red senderista y BTT del Camp de Morvedre, resultando en una selección, descripción y definición de las rutas. Ya en la actualidad el ciclismo produce un flujo considerable de visitantes en la zona de la Baronía, dinamizando la hostelería de la zona (Figura 4).

Figura 4. Vista aérea del mirador del Garbí

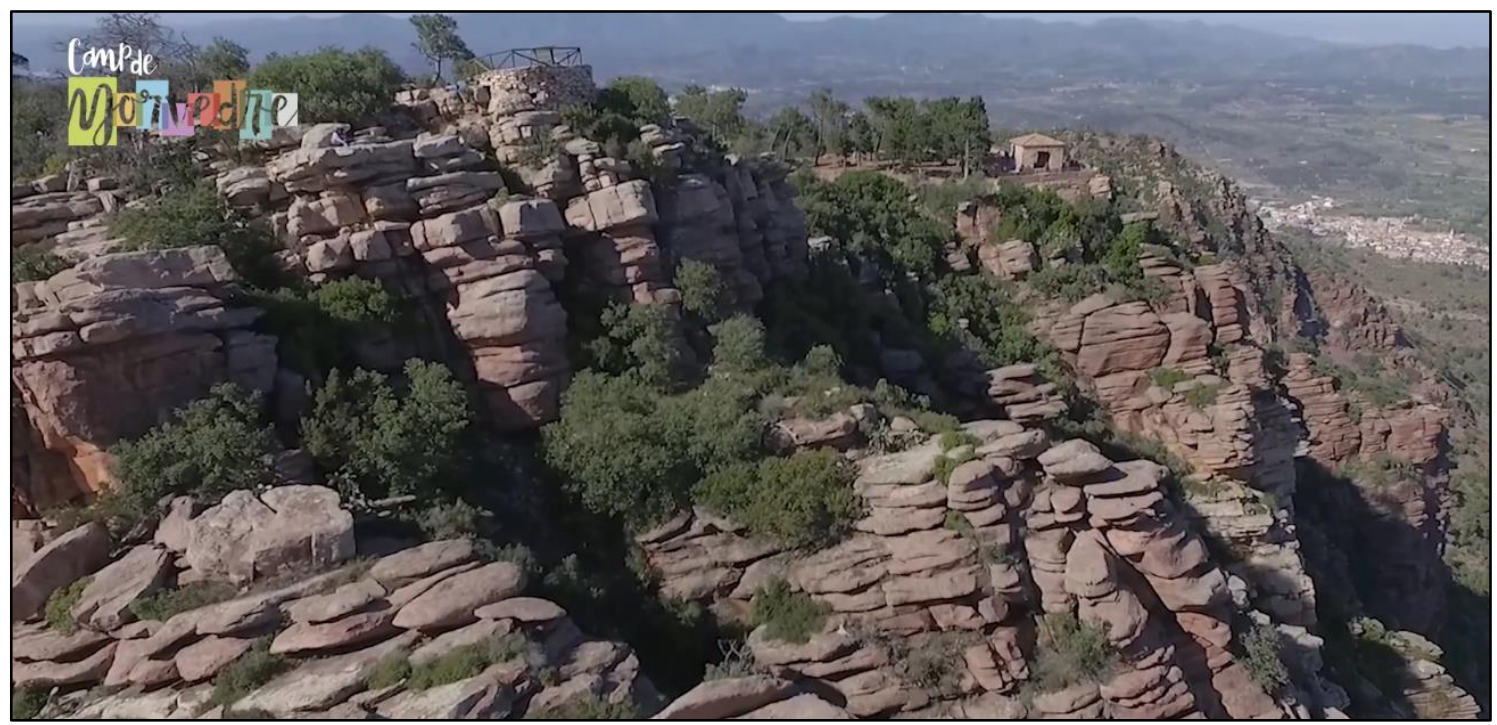

Fuente: Film Office del Camp de Morvedre (https://www.saguntofilmoffice.com/).

\subsection{Futuro del sector turístico}

Una vez finalizadas las tres anualidades del Plan de Gobernanza y Dinamización Turística, y ya dispuestos a analizar los resultados, se produce algo similar a lo que ocurre con los Pactos Territoriales por el Empleo. Encontramos que el inicio de todo es una subvención que se otorga al territorio, para que trabaje en red, de forma cohesionada y cuyos resultados afectan de forma supramunicipal.

En estos casos, la subvención en sí misma es simplemente el germen inicial, el objetivo de este tipo de planes es mantenerse en el tiempo, generar un método de comunicación y 
planificación que trascienda el propio Plan, en su aspecto más administrativo, y que una vez finalizada la subvención continúe en el tiempo.

El Plan de Gobernanza y Dinamización Turística del Camp de Morvedre ha conseguido el impacto que buscaba. No obstante, queda muchísimo trabajo por hacer, pero ha logrado otorgar la identidad suficiente al conjunto de la comarca del Camp de Morvedre para poder promocionarse como destino cohesionado, creando sinergias entre los recursos.

Las bases están colocadas y solo el paso del tiempo podrá determinar si las redes creadas entre las diferentes entidades a causa del Plan son lo suficientemente fuertes para continuar trabajando en la misma línea. Actualmente la colaboración de los diferentes municipios en cuanto a apoyo en acciones turísticas, ha aumentado considerablemente, y el Plan prevé de las herramientas adecuadas para mantenerlo en el tiempo.

El Camp de Morvedre continuará siendo un destino muy competitivo en cuanto a turismo de sol y playa, pero incorporará a su oferta una más que destacable variedad de actividades para competir en otros mercados y para enriquecer la experiencia del turista.

\section{REFLEXIÓN FINAL}

Si hubiera que destacar alguno de los aspectos del Plan de Gobernanza y Dinamización Turística del Camp de Morvedre es su planteamiento de trabajo entre todos y para todos. Cuando hablamos de desarrollo local, la actividad económica, la identidad de un territorio, sus recursos, lugares, cultura y valores intangibles no se limitan únicamente a un término municipal como tal, sino que son la suma de todo el territorio, pudiendo este estar formado por multitud de municipios.

A la hora de desarrollar este tipo de planes, y teniendo en cuenta que para la consecución de los objetivos con éxito es necesaria la colaboración de multitud de agentes, es imprescindible pensar en red, trabajar de forma supramunicipal, establecer contactos de trabajo fluidos, y que todos los actores estén informados de los procesos, acciones que se desarrollan y que además vayan aportando activamente a ese plan conjunto.

En ocasiones, lo que a priori parece la tarea más fácil, que es la comunicación, es la que determina el éxito o el fracaso de este tipo de acciones. El saber recoger adecuadamente las necesidades del territorio, conocer las posibilidades y limitaciones del mismo, así como asegurarse que todo lo diseñado en el plan se implanta y se lleva acabo efectivamente en todos los municipios, vertebrando el territorio, es esencial para que un Plan como el aquí expuesto pueda llegar a buen puerto.

Por todo ello, la suma de esfuerzos y el determinar conjuntamente la dirección a tomar, es lo que produce los efectos tangibles y cohesiona la estrategia turística de todos los municipios de la comarca, que tan bien se complementan entre sí, con la fortaleza actual del turismo de sol y playa, pero sumando todo el potencial en cuanto a turismo deportivo y natural de la zona más interior de la comarca.

La suma de todos los recursos permite una diversificación del producto turístico que hace que el destino sea mucho más atractivo, permite ser cercanos a nuevas tipologías de turista, estar presentes en nuevos mercados y, en definitiva, ser mucho más competitivos, que es uno de los objetivos principales del plan. 


\section{REFERENCIAS}

Farinós, J., Monteserín, O., y Escribano, J. (2018). Cooperación territorial y desarrollo: una mirada desde la escala transregional y de los espacios metropolitanos, rurales y turísticos. Redes: Revista do Desenvolvimento Regional, 23 (3), 35-65.

Velarde, A., y Escribano, J. (2016). El papel de la administración en la gestión y promoción de la Vía Verde de Ojos Negros en su tramo valenciano. En A. R. Ruiz, M. A. Serrano, y J. Plaza (eds.), Treinta años de Política Agraria Común en España. Agricultura y multifuncionalidad en el contexto de la nueva ruralidad (pp. 949-961). Asociación de Geógrafos Españoles (Grupo de Geografía Rural), Óptima Diseño e Impresión. 